\title{
Gender Differences in the Upward Mobility of Black Managers: Double Whammy or Double Advantage?
}

\author{
Stella M. Nkomo \\ University of North Carolina at Charlotte \\ Taylor Cox, Jr. \\ University of Michigan
}

This study draws upon the theory and research on intraorganizational mobility to examine gender differences in the upward mobility of black managers. Results suggest that neither the "double whammy" assumptions nor the "double advantage" assumptions are accurate descriptions of the contemporary experience of black female managers in corporate America. Upward mobility rates were nearly identical for both gender groups. Other findings and the implications of the results for future research are discussed.

In the last 20 years, the subject of women in management has emerged as a significant research field (Freedman \& Phillips, 1988; Larwood \& Gutek, 1987; Nieva \& Gutek, 1982; Larwood \& Wood, 1977). However, researchers in the field have given scant attention to the experience of minority women managers (Nkomo, 1988). At the same time, research on black managers typically focuses on black/white differences in managerial experiences. Only fleeting reference is made to the case of black women managers and the gender issue is typically subordinated to the race issue (Dickens \& Dickens, 1982; Davis \& Watson, 1982; Fernandez, 1975). As a result of these approaches, the study of black women managers has fallen between the boundaries of these two research tracks. Black women managers are subsumed alternately under the category "women or blacks" while the combined category of black women is often ignored. Demographic trends indicate that the U.S. work force is becoming more racially diverse. It is therefore important that researchers give attention to women from various racial and ethnic minority groups in 
order to provide a more complete picture of the experience of women in management. The present study addresses part of this void by examining gender differences in the upward mobility of black managers in organizations.

\section{LITERATURE REVIEW}

\section{Race and Gender}

Much of the limited writing on black women managers has been impressionistic and based on anecdotal explications (e.g., Weathers, 1981). A common issue pervading these writings is the nature of the impact of race and gender on black women in organizations. While most researchers have recognized the effect as cumulative, they differ on whether it is positive or negative. The "two-fer" or "double advantage" theory posits that the sum effect of race and gender is positive while the "double whammy" or "double blind" theory holds that black women suffer a double-negative effect (Ladner, 1971). The "two-fer" theory has generally advocated the proposition that black women enjoy a preferred status vis-à-vis black males. Scoring one affirmative action point because she is black and yet another because she is female, an ambitious black professional woman is said to have assured success (Weathers, 1981). The origins of this argument can be traced back to the historical interpretation of black women's sex roles in social science writings. Black women have often been stereotyped as strong-willed powerful matriarchs, suggesting that the black woman has greater power than the male in the black family and generally enjoys a higher status in society. Some researchers have further suggested that there have been loopholes in racial discrimination that permitted black women to take better advantage of educational opportunities and that black families may have encouraged their daughters rather than sons to continue their education (Fox \& Hesse-Biber, 1984).

Epstein (1973), in a descriptive study of 31 black professional women in prestigious male-dominated professions, argued that the effect of two negatively evaluated ascribed statuses - the sex status of female and the race status of black - did not result in negative consequences but formed a positive matrix for a meaningful career. Epstein (1973) argued that focusing on one of the negatively valued statuses had the effect of raising the worth of the other negative status, thereby creating an offsetting effect. For example, in a white male dominated environment, a black woman is viewed as lacking the "womanly" occupational deficiencies of a white woman - that is, seeking a husband - and the black woman's sex status is given a higher evaluation. Adams (1983) in a study of biracial groups concluded that within a social 
context, black females are more readily accepted in roles of influence than black males. This line of thinking implies that black women in organizations will advance faster and farther than black men because they are perceived to be less threatening. Jones (1986, p. 91), in a study of black managers, argued that "if personal comfort levels are a main criterion for advancement, black women are less threatening and therefore acceptable to white male executives and will advance faster and farther than black men."

In contrast to the two-fer theory, other writers have portrayed black women as victims of a "double whammy." King (1975) has argued that while sexism is injurious to black women, it is the practice of this phenomenon within the context of racism that intensifies the negative experience. Benjamin (1982), in a study of upwardly mobile black women, contends that because of her race and sex, the upwardly mobile black woman occupies an acute marginal position in society, thereby increasing her chances of isolation. This view points to a deficiency in the two-fer theory. In making comparisons between the status of black males and black females, taken on face value the two-fer argument implies that the impact of gender is positive for black women. Arguably, a black female may be considered "safer" than a black male, but the comfort experienced by a white male may result from the fact that she can still be relegated to an inferior status because of her sex. In other words, from the viewpoint of a white male manager a black female represents an anomaly - she is the most different and can be discounted because of her race and gender.

Empirical studies of the effect of race and gender on upward mobility in corporations are difficult to locate (Fernandez, 1981). However, there have been a few relevant studies focusing on the employment experience of black women in management. Brown and Ford (1977) in their study of the employment of black MBA graduates found black female MBAs to be victims of both more job entry and job progression discrimination than black males. Black female MBA graduates in their study had significantly lower starting salaries than their black male peers from the same school. In a study of black accountants in public accounting firms, Aiken (1976) found that none of the women reported having excellent or outstanding experiences, while $29 \%$ of the males in this study reported excellent and outstanding work experiences. Hitt, Zikmund, and Pickens (1982), in a study of the existence of race and sex discrimination in the evaluation of job applicant resumes sent to personnel directors of 200 corporations across the United States, found the interaction effect (race by sex) for replies was not statistically significant. Thus being a black female did not increase the number of positive responses to resumes. Irons and Moore (1985), in their survey of blacks in the banking industry, found that although there was greater growth in the number of black women at the management level compared to black men, black wom- 
en were concentrated in the low level operations type jobs, small branch management, and staff functions, and not in the commercial lending or investment functions of banks. Fulbright (1985), in her study of 25 middleand senior-level black female managers in private-sector employment, found that black female managers are likely to encounter the same limits on their mobility that all managers might encounter, and additionally, they are likely to encounter limits to their mobility on account of their race and sex. While Fulbright's study did address the issue of mobility, she did not have a comparison group of black males and was unable to directly compare the promotion rates of the two groups.

Research on gender differences in career progress is limited and the reported research does not include information on race differences. Yet the results of these studies do have implications for the present study. Miner (1974) and Rousell (1974) have reported that women are less likely to be promoted than men. Landau and Amoss (1986) found that women MBAs took only eight to ten years to reach the invisible ceiling on their careers. However, Tsui and Gutek (1984) found that women managers seemed to be promoted faster than their male counterparts. Stewart and Gudykunst (1982) found gender differences in the factors affecting number of promotions. For example, they found that length of tenure was positive for males and negative for females. Larwood and Gattiker (1987), in a study of the career development of 215 successful men and women (the race composition of the sample was not specified), concluded that compared to men, women are faced with more constraints on their career progress because of discrimination and stereotyping. While this research is less than uniform in its findings, it does suggest that promotion rates and intraorganizational mobility factors may differ based on gender. Because of problems such as sex discrimination and socially defined sex roles, women face fundamentally different situations in developing careers than do men (Larwood \& Gattiker, 1987; Larwood \& Gutek, 1987; Larwood, Azwaukowski, \& Rose, 1987).

\section{Present Study}

The above review highlights the ongoing debate on the issue of the double advantage of black women and the neglect of race in studies focusing on the careers of women managers. With the exception of the Fulbright (1985) study, the authors could not find any empirical studies that specifically addressed the double advantage theory in the context of the upward mobility of black women managers. There is an additional need to explicitly incorporate gender in the study of black managers and not treat is as a peripheral issue. 
Based on the above review, this paper reports on research designed to test the veracity of the double advantage and double whammy theories in upward mobility of experience of black managers. The outcomes predicted by the respective theories are as follows:

Hypothesis 1: Black women will experience a higher rate of upward mobility than their black male counterparts.

Hypothesis 2: Black women will experience a lower rate of upward mobility than their black male counterparts.

In addition to testing these two competing hypotheses, we also examine the differences in the factors predicting upward mobility for black male and female managers.

\section{Mobility Factors}

Organizational research on upward mobility suggests that mobility is a function of both organizational and individual attributes (Anderson, Milkovich, \& Tsui, 1981). In selecting variables relevant to the present study, we chose variables that had some empirical support and those identified through a pilot study of 50 white and black managers mostly from the banking industry. The approach used in the study treats actual mobility (number of promotions) as the dependent variable, and individual and organizational characteristics as predictors.

Our study included six individual-level determinants of upward mobility (job performance, company seniority, line management assignments, job involvement, mentor help, and interracial social interaction). Past job performance has been reported as a basis for promotion (Beehr, Taber, \& Walsh, 1980; Gemmill \& DeSalvia, 1977; Taylor, 1975). However, the extent to which performance ratings are actually used is less clear (Taylor, 1975). Further, the validity of past performance ratings may be confounded by other factorse.g., race and sex (Cox \& Nkomo, 1986). Seniority has generally been found to correlate positively with advancement (Beehr et al., 1980), and some researchers have argued that the slow progress of black managers in organizations is largely due to the limited time they have been in management positions.

Job involvement has been defined as the perceived importance of work in one's life or the degree of psychological identification with one's work, and has been shown to be related to general ambition and upward mobility desires (Hall, Goodale, Rabinowitz, \& Morgan, 1978). The inclusion of this variable permits a test of the proposition that black women in corporations are less ambitious than black men and more likely not to seek opportunities for advancement. 
Line management assignments may be an important factor in gaining promotion for black managers. Larwood and Gattiker (1987) found that line and professional positions are linked with hierarchical success. The pilot study indicated that black managers with line experience had greater upward mobility. This may be an even more critical factor for black women. Irons and Moore (1985) reported that black women in the banking industry tended to be heavily concentrated in "staff" positions.

Mentor help and social relationships in the informal network have been identified as important contributors to upward mobility in organizations. Studies of mentoring relationships suggest that it can be instrumental in supporting both personal growth and career advancement (Kram, 1985). The literature on mentoring shows that mentors are most likely to select proteges perceived to be similar. Since white males are the major mentor population group in most organizations, it is likely that preferences for proteges will be largely confined to white men (same race and sex), white women (same race), and black men (same sex). Because of the combined difference of race and gender black women are likely to have the least access to mentors.

Social and political networks in organizations often provide managers with information about their jobs, knowledge of opportunities, and support when choices are made about promotions (Thompson \& DiTomasso, 1988). To a certain extent black managers who participate in interracial social networks should experience higher rates of mobility. However, Kanter (1980) has argued that people feel most comfortable personally and professionally with those most like themselves. Black women managers may be the group least likely to have access to the benefits of informal social networks in organizations.

Organizational factors also influence upward mobility. Size of an organization and frequency of job vacancies are expected to have a positive impact on an individual's opportunities for advancement (Grusky, 1961). Other organizational factors found to influence promotion decisions include affirmative action/equal employment opportunity programs (Pedigo \& Meyer, 1979) and the percentage of minorities in the workplace (Harlan \& Weiss, 1982). Harlan and Weiss (1982) found a curvilinear relationship between gender bias and the proportion of women in an organization, with high resistance to the first female managers and a decrease in resistance until women reached $10-15 \%$ of the managerial category, at which point there was a rapid rise in resistance. The same phenomenon may apply to race bias.

\section{METHOD}

\section{Sample}

Confidential questionnaires were mailed to all 834 nonstudent members of the National Black MBA Association (NBMBAA) who were employed 
in full-time positions. The NBMBAA is a nonprofit organization of black MBAs. The NBMBAA was selected to obtain data on a large cross section of black managers.

A total of 375 questionnaires were returned for a response rate of $45 \%$. Eight of the questionnaires were unusable and another 84 were from respondents working in nonmanagement jobs. Since the focus of this study was on black managers, the data analysis includes only those respondents who were at the first level of management or higher. Our sample size for the data analysis was 283 respondents, 165 men and 118 women.

The average age of the sample was 35 and they had an average of 5.2 years of seniority with their employer and 6.7 years of total related work experience. The average number of employers was 2.09 . Geographically, $45 \%$ of the respondents were from the Midwest, $21 \%$ from the Northwest, 20\% in the Northeast, and 8 and $6 \%$, respectively, in the Southeast and Southwest. A wide cross section of industries are represented in the sample. A majority of the sample was employed in the private sector.

\section{Questionnaire}

The questionnaire included questions on the mobility factors and biographical information (job title, industry worked for, educational background, sex, and salary level). These questions were developed by examining relevant items from other studies and through our pilot study. The questionnaire was five pages long and was pretested in our pilot study. (A copy of the full questionnaire is available from the first author.)

Dependent Variable. Upward mobility was measured by total number of promotions received, present management level, and promotion rate (promotions/years of service). The use of the latter measure controls for differences in seniority.

Independent Variables. The first set of independent variables measured the individual factors that included the respondent's company seniority and recent job performance ratings. Respondents were also asked to indicate the number of line assignments they had received. Following a procedure used by Hall et al. (1978), job involvement was measured by four Likert-type items from a scale developed by Lodahl and Kejner (1965). A similar scale was used by Slocum, Cron, Hansen, and Rawlings (1985), and they reported an alpha coefficient of .79. The alpha for this study was .75. Mentor help was measured by a single item that asked respondents to rate the extent to which his/her career had been aided by a mentor(s) on a 7-point response format. The term mentor was defined as "a person in a higher organizational position who had been particularly helpful and supportive to your career." Respondents were also asked to indicate, on a scale of (1) never to (7) very 
frequently, "How often do you participate in social activities with peers or supervisors of other races off the job?"

The second set of independent variables centered on organizational factors. These variables were organization size (measured by number of employees), number of management levels in the organization, percentage of black employees, organizational commitment to EEO/AA programs, and frequency of management vacancies. The latter two variables were measured using a 7-point response format anchored (1) low and (7) high.

Career satisfaction was measured by two items (alpha $=.65$ ) taken from a scale developed by Beehr et al. (1980). A final item measured respondents' satisfaction with their rate of advancement: "How rapidly have you moved up in this company?" Response categories ranged from much less rapidly than expected to much more rapidly than expected.

\section{RESULTS}

Descriptive statistics for key variables appear in Table $I$, along with the results of two-tailed $t$ tests for the significance of differences between the means. The correlation matrix for the study variables is shown in Table II. The intercorrelations revealed no evidence of extreme multicollinearity (i.e., $r \mathrm{~s}>.80$ ).

Table I. Descriptive Data for Males and Females

\begin{tabular}{|c|c|c|c|c|c|}
\hline \multirow[b]{2}{*}{ Variables } & \multicolumn{2}{|c|}{ Males $(n=165)^{e}$} & \multicolumn{2}{|c|}{ Females $(n=118)^{e}$} & \multirow[b]{2}{*}{$p>t^{\circ}$} \\
\hline & Mean & $S D$ & Mean & $S D$ & \\
\hline 1. Company seniority & 5.60 & 5.08 & 4.44 & 3.91 & .05 \\
\hline 2. Job performance & 4.17 & 1.31 & 4.53 & 1.26 & .05 \\
\hline 3. Line assignments & 1.89 & 2.12 & 1.60 & 1.79 & ns \\
\hline 4. Mentor help ${ }^{b}$ & 3.38 & 1.81 & 3.63 & 1.74 & ns \\
\hline 5. Job involvement $t^{c}$ & 3.42 & .79 & 3.23 & .77 & ns \\
\hline 6. Interracial socializing & 3.73 & 1.47 & 3.63 & 1.65 & $\mathrm{~ns}$ \\
\hline 7. Total promotions & 1.03 & 1.38 & .93 & 1.33 & ns \\
\hline 8. Promotions/years & & & & & \\
\hline of service & .24 & .35 & .22 & .40 & ns \\
\hline $\begin{array}{l}\text { 9. Rapidity of } \\
\text { advancement } t^{b}\end{array}$ & 2.87 & 1.56 & 3.41 & 1.66 & 01 \\
\hline 10. Career satisfaction ${ }^{b}$ & $\begin{array}{l}2.87 \\
4.02\end{array}$ & $\begin{array}{l}1.50 \\
1.82\end{array}$ & $\begin{array}{l}3.41 \\
4.19\end{array}$ & $\begin{array}{l}1.00 \\
1.77\end{array}$ & $\begin{array}{l}.01 \\
\text { ns }\end{array}$ \\
\hline 11. Age & 36.04 & 6.97 & 33.14 & 5.50 & .001 \\
\hline 12. Salary ${ }^{d}$ & 3.47 & 1.59 & 2.87 & 1.18 & .001 \\
\hline 13. Management level & 2.23 & 1.60 & 2.11 & 1.30 & ns \\
\hline
\end{tabular}

\footnotetext{
${ }^{a}$ Two-tailed tests.

${ }^{b}$ Seven-point Likert scale.

${ }^{c}$ Four items measured on 7 -point scale.

${ }^{d}$ Using midpoint of the salary range $(2=35,500 ; 3=44,000 ; 4=53,000)$.

${ }^{e}$ Nonmanagement respondents were omitted from the analysis.
} 


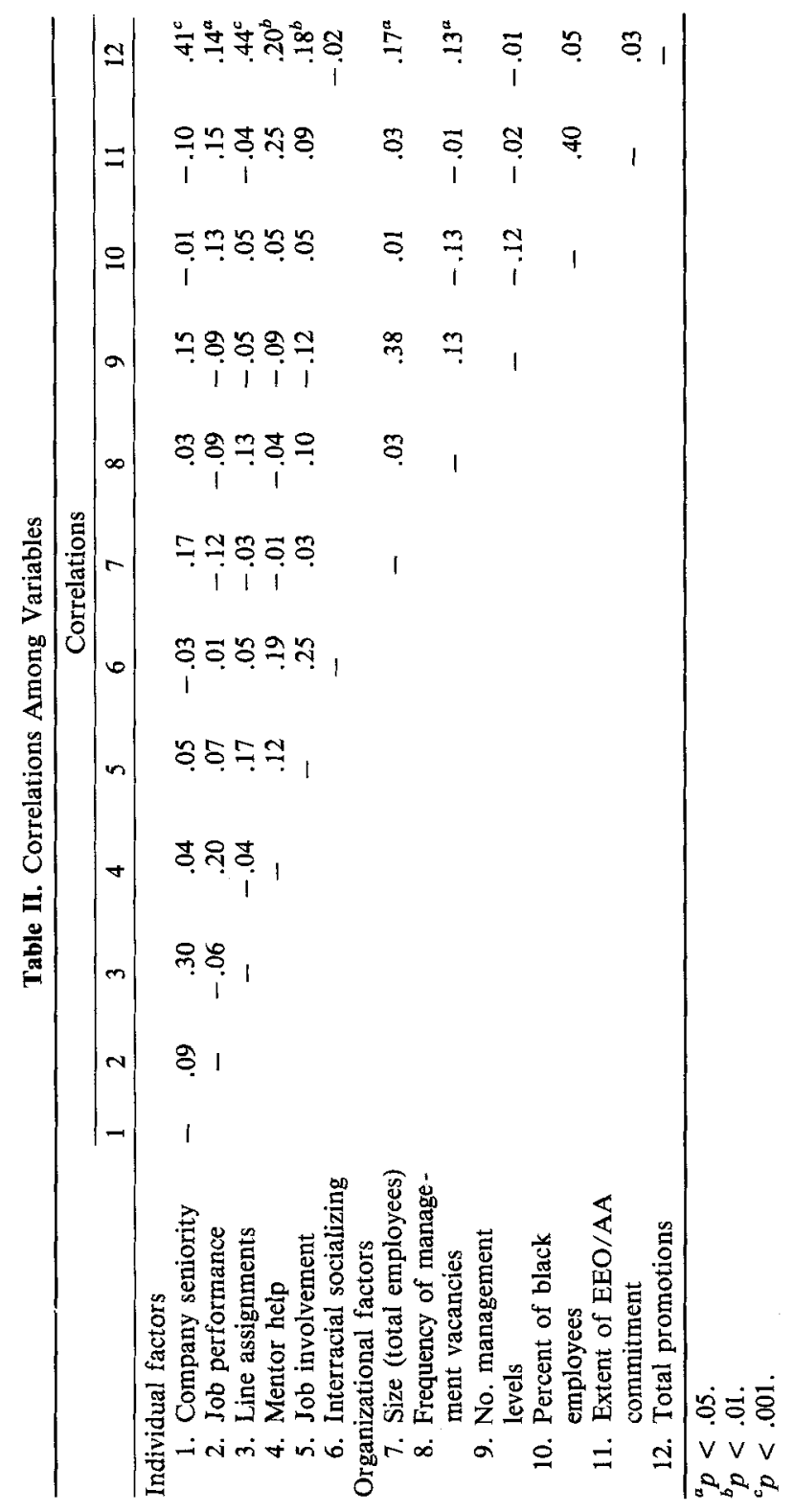


We note from Table I that black men and women were very similar on the extent of participation in interracial social activities, the level of career satisfaction, and on all three measures of upward mobility (total number of promotions, promotion rate, and present management level). However there are significant differences between the gender groups on several variables including seniority (men have more), job performance (women have higher ratings), rapidity of advancement in accordance with expectations (men express lower satisfaction with the rate of advancement), age (men are older), and salary (women make less). The hypotheses in the first part of this study focused on whether the rates of advancement for black men and women managers would be the same. The results in Table I indicate there were no significant differences between the two groups on total number of promotions (1.03 for men and .93 for women), present management level (2.23 for men and 2.11 for women), and promotion rate (.24 and .22), respectively. The latter measure is especially important because it compensates for the significant differences in seniority between the gender groups.

The two competing hypotheses were further tested using analysis of covariance. Two dependent variables (total promotions and hierarchical level) were predicted by models using gender as the factor variable and a set of seven covariates: organization size, vacancy rates of management positions, total number of management levels, extent of EEO/AA commitment, total work experience, company seniority, and job performance. This analysis allowed for a conservative test of gender difference in upward mobility rates while controlling for a large number of potentially confounding influences. Results indicated no significant gender differences in upward mobility as measured by hierarchical level and total promotions $(F=.02$, and .41 , respectively). Therefore, neither the double whammy nor the double advantage hypotheses were supported by the data.

The second part of this study examined the extent to which mobility factors differ by gender. A multiple regression analysis was performed which treated the six individual factors and the five organizational factors as predictors of the total number of promotions received at the present employer. Due to missing data, the sample size for the regression (267) was slightly smaller than for the earlier analyses. Results appear in Table III.

The overall power of the model for explaining intraorganizational mobility was very similar for the two groups $\left(R^{2}=.34\right.$ for men and .32 for women). An examination of the beta coefficients, however, indicates that only two variables, line assignments and company seniority, were significant predictors $(p<.001)$ for men, while for women organization size and mentor help were also significant (see Table III). Joint $F$ statistics indicated that the collective impact of the organizational factors was significant only for the women $(F=2.47, p<.05)$. The joint significance test of the individual 
Table III. Multiple Regression Analysis Predictors of Promotion Rates for Males and Females

\begin{tabular}{lccc}
\hline & $\begin{array}{c}\text { Males } \\
(N=156) \\
\text { Beta }\end{array}$ & $\begin{array}{c}\text { Females } \\
(N=111) \\
\text { Beta }\end{array}$ & $\begin{array}{c}t \text { Value } \\
\text { difference in } \\
\text { regression weights }\end{array}$ \\
\hline Organizational factors & .10 & $.34^{d}$ & $5.4^{d}$ \\
$\quad$ Size (total employees) & .11 & .05 & $-16.4^{d}$ \\
Frequency of vacancies & -.08 & -.13 & $-3.5^{c}$ \\
No. management levels & .08 & -.02 & $17.1^{d}$ \\
Percent black employees & .10 & -.06 & $-4.1^{d}$ \\
Extent of EEO/AA & & & \\
(Joint significance test of & 1.66 & $2.47^{b}$ & \\
$\quad$ organizational factors-F & & & $1.0 \mathrm{~ns}$ \\
Individual factors & $.31^{d}$ & $.31^{c}$ & $-2.17^{b}$ \\
Company seniority & .04 & .06 & $14.2^{d}$ \\
Job performance & $.36^{d}$ & $.21^{b}$ & $5.4^{d}$ \\
Line assignments & .09 & $.31^{b}$ & $-9.6^{d}$ \\
Mentor help & .05 & .14 & \\
Job involvement & -.07 & -.14 & \\
Interracial socializing & & & \\
(Joint significance of individual & $10.5^{d}$ & $5.18^{d}$ & \\
factors-F =) & .34 & .32 & \\
Overall $R^{2}$ (adjusted) & $7.11^{d}$ & $4.38^{d}$ & \\
Overall $F$ & & & \\
\hline
\end{tabular}

${ }^{a}$ Test used unstandardized regression weights.

${ }^{b} p<.05$.

$c_{p}<.01$.

${ }^{d} p<.001$,

factors, while significant for both groups, was largely for the men $(F=10.5$, $p<.001$ ).

Examination of standardized regression coefficients allows for determination of the relevant contribution of the independent variables within a particular analysis; however, it does not allow for a comparison of the contributions of particular variables across subgroups. In order to compare the data with respect to the contribution of the independent variables in predicting number of promotions, it is necessary to examine differences in the unstandardized regression weights across the two groups. The significance of the difference of the regression weights was tested with the $t$ formula provided by Arnold (1982). The relevant $t$ tests are shown in the last column of Table III. All but two of the independent variables had a significant differential impact for black men and women managers. Size of the organization, percent of black employees, mentor help, and job involvement were more important to the advancement of black women than men, while frequency of management vacancies, number of management levels, extent of equal employ- 
ment opportunity/affirmative action, line assignments, and interracial social activity were more important to the advancement of black men. Number of management levels and interracial social activity had a greater negative impact on predicting the number of promotions for black women than black men. Finally, the perceived extent of equal employment/affirmative action opportunity was a positive contributor for men but negative for the women in the study. However, this variable was not statistically significant for either group. In summary, the data indicate significant differences in predictors of upward mobility success for black men and women managers. The data seem to suggest that black women managers advance better in large organizations where they have some mentor help. While seniority was equally important to both groups, having line management experience was more important for the advancement of men.

\section{DISCUSSION}

The results of this research suggest that neither the double advantage theory nor the double whammy argument are accurate descriptions of the contemporary experience of black women managers in corporate America. Upward mobility rates were nearly identical between the gender groups. Another interesting element of the findings is that black men reported much less satisfaction with the rate of advancement than black women. On the question, "how rapidly have you moved up in this company?" with anchors ranging from much more rapidly than expected to (5) much less rapidly than expected (1), black men had an average response of 2.8 compared to 3.4 for women, a difference that was significant $(p<.01)$. It is likely that this result reflects a continuing difference between males and females in the pressure (perhaps self-imposed) to compete and excel. Black men may be especially sensitive to such pressure because of years of being maligned for underaccomplishment and inferiority and the tradition of the male bread-earner responsibility. Fleming (1982) found that the career orientation of black men may be a product of what she called "compensatory motivational dynamics." That is the belief among black men in the stereotype of the unreliable black male and the more reliable white male. It is also possible, however, that the different perceptions of advancement satisfaction reflect more realistic expectations by black women about advancement rates, although it is not clear what the source of this difference may be.

For both groups the individual factors were more important than the organizational factors. This result has to be interpreted with caution, however. Several of the factors defined as individual factors are significantly influenced by organizational actions. For example, line assignments are determined by 
decisions made about job placement and staffing from upper level officers. The finding that mentor help was more important to the advancement of black women than black men and that black women reported slightly greater use of mentors warrants further study. It would be important to identify the race and sex of the mentor in trying to understand this difference. Unfortunately, we were not able to collect that information from respondents. However, there is some support in the literature for our finding. Thomas (1986), in a study of the impact of race on mentoring and sponsorship in organizations, found that black males tend to form mentor relationships later into their career than other race-gender groups. He speculates that there are differential issues confronting black men and women in establishing crossrace mentoring relationships.

Interracial social activity was not a predictor of success for either group. This may indicate that the often heard advice to minorities to "join the informal network" for success is not sound. In fact, the negative sign on the coefficients may even suggest that such advice may be detrimental to career advancement.

One of the important findings of this research is that the predictors of upward mobility may not be the same for men and women within the racial minority group of black managers. This finding underscores the complexity of understanding the interaction between race and gender in organizations. Studies focusing solely upon gender or race may overlook important relationships between these variables. A clear direction for extending this inquiry is to consolidate what has now been learned about factors impacting promotion for the various race-sex groups to plan theory-driven research using cross-race, cross-gender designs. While this study is helpful in identifying some of the gender differences in upward mobility among black professionals, future research should seek a sample with longer work tenure and minimize the reliance on self-report data. Future studies should also examine the impact of work and family on advancement of black women in management careers. Although the design of the present study is less than ideal, the reported research makes a contribution to empirically examining the double advantage versus double whammy effect of race and gender in organizations.

\section{REFERENCES}

Adams, F. Aspects of social context as determinants of black women's resistance to challenges. Journal of Social Issues, 1983, 39, 69-79.

Aiken, W. The black experience in large public accounting firms. In D. Ford (Ed.), Readings in minority-group relations. La Jolla, CA: University Associates, 1976. 
Anderson, J., Milkovich, G., \& Tsui, A. A model of intraorganizational mobility. Academy of Management Review, 1981, 6, 529-538.

Arnold, H. J. Moderator variables: A clarification of conceptual, analytic, and psychometric issues. Organizational Behavior and Human Performance, 1982, 29, 143-174.

Beehr, T., Taber, \& Walsh, J. Perceived mobility channels: Criteria for intraorganizational job mobility. Organizational Behavior and Human Performance, 1980, 26, 250-264.

Benjamin, L. Black women achievers: An isolated elite. Sociological Inquiry, 1982, 52, 141-151.

Brown, H., \& Ford, D. An exploratory analysis of discrimination in the employment of black MBA graduates. Journal of Applied Psychology, 1977, 6, 50-56.

Cox, T., \& Nkomo, S. Differential performance appraisal criteria: A field study of black and white managers. Group and Organization Studies, 1986, 11, 101-119.

Davis, G., \& Watson, G. Black life in corporate America: Swimming in the mainstream. New York: Doubleday, 1982.

Dickens, F., \& Dickens, J. The black manager: Making it in the corporate world. New York: Amacom, 1982.

Epstein, C. Positive effects of the multiple negative: Explaining the success of black professional women. American Journal of Sociology, 1973, 78, 913-935.

Fernandez, J. Black managers in white corporations. New York: Wiley, 1975.

Fernandez, J. Racism and sexism in corporate life. Lexington, MA: D. C. Heath \& Company, 1981.

Fleming, J. Fear of success in black male and female graduate students: A pilot study. Psychology of Women Quarterly, 1982, 6, 327-340.

Fox, M. F., \& Hesse-Biber, S. Women at work. Palo Alto, CA: Mayfield, 1984.

Freedman, S. M., \& Phillips, J. S. The changing nature of research on women at work. Journal of Management, 1988, 14, 231-251.

Fulbright, K. The myth of the double-advantage: Black female managers. Review of Black Political Economy, 1985, 14, 33-45.

Gemmill, G., \& DeSalvia, D. The promotion beliefs of managers as a factor in career progress: An exploratory study. Sloan Management Review, 1977, 18, 75-81.

Grusky, O. Corporate size, bureaucratization, and managerial succession. American Journal of Sociology, 1961, 67, 261-269.

Jones, E. W. Black managers: the dream deferred. Harvard Business Review, 1986, 64, 84-93.

Hall, D., Goodale, J., Rabinowitz, S., \& Morgan, M. Effects of top down departmental and job change upon perceived employee behavior and attitudes: A natural field experiment. Journal of Applied Psychology, 1978, 63, 62-73.

Harlan, A., \& Weiss, C. Sex differences in factors affecting managerial career advancement. In P. Wallace (Ed.), Women in the workplace: Boston. Auburn Publishing Company, 1982.

Hitt, M., Zikmund, W., \& Pickens, B. Discrimination in industiral employment: An investigation of race and sex bias among professionals. Work and Occupations, 1982, 9, $217-231$.

Irons, E., \& Moore, G. Black managers: The case of the banking industry. New York: Praeger Publishers, 1985.

Kanter, R. A tale of " $o$ ": On being different in an organization. New York: Harper \& Row, 1980.

King, M. Oppression and power: The unique status of the black woman in the American political system. Social Science Quarterly, 1975, 56, 123-133.

Kram, K. E. Mentoring at work: Developmental relationships in organizational life. Glenview, IL: Scott Foresman, 1985.

Landau, J., \& Amoss, L. Myths, dreams and disappointments: Preparing women for the future. In L. Moore (Ed.). Not as far as you think. Lexington, MA: Lexington Press, 1986.

Ladner, J. Tomorrow's tomorrow: The black woman. New York: Doubleday, 1971.

Larwood, L., \& Gattiker, U. A comparison of career paths used by successful women and men, In L. Larwood \& B. Gutek (Eds.), Women's career development. Beverly Hills, CA: Sage Publications, 1987.

Larwood, L., \& Gutek, B. (Eds.), Women's career development. Beverly Hills, CA: Sage Publications, 1987. 
Larwood, L., Azwajkowski, E., \& Rose, S. Sex and race discrimination resulting from managerclient relationships: Applying rational bias theory of managerial discrimination. Sex Roles, $1987,18,9-29$.

Larwood, L., \& Wood, M. Women in management. Lexington, MA: D. C. Heath, 1977.

Lodahl, T. M., \& Kejner, M. The definition and measurement of job involvement. Journal of Applied Psychology, 1965, 49, 24-33.

Miner, J. B. Motivation to manage among women: Studies of college students. Journal of Vocational Behavior, 1974, 5, 241-250.

Nieva, V., \& Gutek, B. Women and work: a psychological perspective. New York: Praeger, 1982.

Nkomo, S. Race and sex: The forgotten case of the black female manager. In S. Rose \& L. Larwood (Eds.). Women's careers: pathways and pitfalls. New York: Praeger, 1988.

Pedigo, P., \& Meyer, H. Management promotion decisions: The influence of affirmative action restrictions. Paper presented at the meeting of the Academy of Management, Atlanta, GA, 1979.

Rousell, C. The relationships of sex of department heads to department climate. Administrative Science Quarterly, 1974, 19, 211-220.

Slocum, J. W., Cron, W. L., Hansen, R. W., \& Rawlings, S. Business strategy and the management of plateaued employees. Academy of Management, 1985, 28, 133-154.

Stewart, L. P., \& Gudykunst, W. B. Differential factors influencing the hierarchical level and number of promotions of males and females within an organization. Academy of Management Journal, 1982, 25, 586-597.

Taylor, R. Preferences of industrial managers for information sources in making promotion decisions. Journal of Applied Psychology, 1975, 60, 269-272.

Thomas, D. An intra-organizational analysis of black and white patterns of sponsorship and dynamics of cross-racial mentoring. Unpublished doctoral dissertation, Yale University, New Haven, CT, 1986.

Thompson, D., \& DiTomasso, N. Ensuring minority success in corporate management. New York: Plenum Publishing, 1988.

Tsui, A., \& Gutek, B. A role set analysis of gender differences in performance, affective relationships, and career success of industrial middle managers. Academy of Management Jounral, 1984, 27, 619-635.

Weathers, D. Black executives: Winning under the double whammy. Savvy, 1981, 2, 34-40. 